\title{
Metalinguistic proposals
}

\author{
Article
}

Accepted Version

Hansen, N. (2021) Metalinguistic proposals. Inquiry: An Interdisciplinary Journal of Philosophy, 64 (1-2). pp. 1-19. ISSN 1502-3923 doi:

https://doi.org/10.1080/0020174X.2019.1658628 Available at https://centaur.reading.ac.uk/83389/

It is advisable to refer to the publisher's version if you intend to cite from the work. See Guidance on citing.

To link to this article DOI: http://dx.doi.org/10.1080/0020174X.2019.1658628

Publisher: Taylor \& Francis

All outputs in CentAUR are protected by Intellectual Property Rights law, including copyright law. Copyright and IPR is retained by the creators or other copyright holders. Terms and conditions for use of this material are defined in the End User Agreement.

\section{$\underline{\text { www.reading.ac.uk/centaur }}$}

\section{CentAUR}

Central Archive at the University of Reading

Reading's research outputs online 


\title{
Metalinguistic Proposals*
}

\author{
Nat Hansen \\ Forthcoming in Inquiry
}

\begin{abstract}
This paper sets out the felicity conditions for metalinguistic proposals, a type of directive illocutionary act. It discusses the relevance of metalinguistic proposals and other metalinguistic directives for understanding both small- and large-scale "linguistic engineering" projects, "essentially contested concepts", metalinguistic provocations, and the methodology of ordinary language philosophy. Metalinguistic proposals are compared with other types of linguistic interventions, including metalinguistic negotiation, conceptual engineering, lexical warfare, and ameliorative projects.
\end{abstract}

Keywords: conceptual engineering, conceptual pacts, essentially contested concepts, metalinguistic negotiation, ordinary language philosophy, speech acts

\section{Metalinguistic proposals}

Metalinguistic proposals are speech acts that involve an intention for an audience to come to have a reason to use or understand the use of a linguistic expression in a particular way. They are related to what Barker (2002, p. 2) calls a "metalinguistic use" of language, which "communicate[s] something about how to use a certain word appropriately", Haslanger's (2012) "ameloriative projects", and what Plunkett and Sundell (2013) call a "metalinguistic negotiation", or what Ludlow (2014) calls "lexical warfare", and they can play a role in what has been called "conceptual engineering" (Cappelen, 2018), "conceptual ethics" (Burgess and Plunkett, 2013), and "linguistic interventions" (Sterken, 2019). The following passage, which occurs in the context of an online debate over whether to use the expressions "battle rifle" and "assault rifle" to describe certain firearms, makes a metalinguistic proposal in its final line (linguistic errors and inconsistency in observation of the use/mention distinction are preserved from the original).

*Thanks to Eliot Michaelson, Rachel Sterken, audiences at the Uppsala Online Speech Workshop, the New College for the Humanities Cognitive Science Research Group, and an anonymous referee for discussion of the issues in this paper. I gratefully acknowledge support from Leverhulme Research Project Grant RPG-2016-193 and a University Research Fellowship from the University of Reading. 
(1) While in the military these terms were never used. It was always a rifle, a pistol, a machine gune $[\mathrm{sic}]$. In fact only until I was out of the military for sometime did I ever hear the term "battle rifle" ever used. These are just sensationalist terms. "Battle rifle" is used to portray the myth that larger caliber is more legit or capable for combat, while assault rifle today is simply used by political forces to deny access to weaponry.

\section{Both are stupid. It's a rifle. ${ }^{1}$}

The commentator makes a metalinguistic proposal that speakers should use the term "rifle" and not "assault rifle" or "battle rifle" to refer to a certain category of firearm.

Here's another example, this time of a speaker reporting a metalinguistic proposal being made:

(2) In the early-1980s, I attended an interesting presentation on the future of office automation. The speaker, a technology expert from Rand Corp., explained the semantic imperative for talking about keyboarding: typing was a (low status) secretarial skill, while keyboarding implied a higher status skill tied to computers. The semantic rebranding of typing as keyboarding, the Rand expert explained, would make learning keyboarding (aka typing) more acceptable to mid- and high-level managers and professionals. ${ }^{2}$

The expert from RAND is reported as making a proposal (a call for "semantic rebranding") that "keyboarding" replace "typing" on the grounds that "typing" would be associated with a low-status secretarial skill, while "keyboarding" would not.

Metalinguistic proposals are a sub-category of what Bach and Harnish (1979) call advisories, a type of speech act in which a speaker expresses "the belief that doing some action is a good idea, that it is in the hearer's interest", and the speaker's "intention that $\mathrm{H}$ [the hearer] take this belief of [the speaker's] as a reason to act". In a metalinguistic proposal, the relevant action that the speaker believes is a "good idea" is using an expression in a particular way. In making a metalinguistic proposal, the speaker also has the perlocutionary intentions that the hearer take the speaker to believe that the speaker actually has the attitudes she is expressing and that the hearer adopt the proposed use she is being advised to adopt (Bach and Harnish, 1979, p. 49). Bach and Harnish distinguish "literal" advisories, which "are imperative in form", from "indirect" advisories that are "performed using declaratives like 'You should' or 'It would be a good idea to"” (p. 289 n. 3). Advisories (including metalinguistic proposals) can be performed even more indirectly, with sentences that might appear at first glance to be assertions or some other form of constative speech act, as (1) exemplifies: the speaker proposes that the terms "assault rifle" and "battle rifle" should be dropped by saying "Both are stupid. It's a rifle".

Bach and Harnish's account of advisories should be slightly amended to allow for the fact that proposals often involve the intention that the hearer accept, as reasons for

\footnotetext{
${ }^{1}$ http://www.thefirearmblog.com/blog/2014/09/24/firearms-semantics-battle-rifle-assault-rifle/

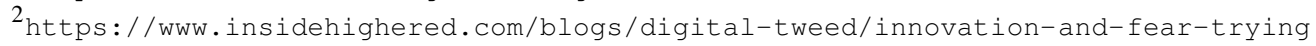


the proposed act, not just the speaker's belief that performing the act is a good idea, but whatever additional reasons that the speaker gives in favor of performing the act. The author of (1) is expressing the belief that calling a particular category of firearms "rifles", rather than "battle rifles" or "assault rifles" is a good idea, and offers a couple of reasons in favor of that proposal that he intends the audience to take as reasons to adopt that use. I propose that when it is the speaker's belief alone that is offered as a reason for the proposed act, the resulting act should be called a bare (metalinguistic) proposal.

According to Bach and Harnish's taxonomy of speech acts, the category of advisories of which metalinguistic proposals are a type is itself a sub-category of directives (Bach and Harnish 1979, p. 47; Austin 1975 calls this category "exercitives"). There are other metalinguistic speech acts that can be classified as types of the other sub-categories of directives, including requirements, prohibitives, and permissives. Accordingly, a speaker might

- require a hearer to use an expression in a particular way (requirement)

- forbid a hearer from using an expression in a particular way (prohibitive)

- allow a hearer to use an expression in a particular way (permissive)

Metalinguistic requirements, prohibitives, and permissives are what Langton (1993, p. 305) calls "authoritative illocutions", which can only be performed by speakers who hold relevant forms of authority over their hearers. For example, a journal editor could require an author to use "they" and "their" as gender-neutral pronouns instead of "he" and "his" as a condition of publishing in their journal. ${ }^{3}$ And certain large-scale linguistic engineering projects, such as Mustafa Kemâl (Atatürk)'s project to "rid Turkish of many learned Arabic loanwords and heavy Arabicized wordings" (Hagège, 2005, p. 105), or the regulation of modern Hebrew by the Academy of the Hebrew Language, which sets linguistic policies which are "binding on all government agencies" in Israel, rely on issuing authoritative metalinguistic directives backed by state power. ${ }^{4}$

In contrast with metalinguistic directives that are backed by explicit authority, "ordinary" (non-authoritative) speakers can make metalinguistic proposals. Some metalinguistic proposals are backed by reasons that justify the speaker's belief that using a particular expression in a particular way is a good idea, as in (1-2). The author of (1) argues against using the expression "battle rifle" for the reason that it perpetuates a myth, and against using the expressions "assault rifle" for the reason that it is used by "political forces to deny access to weaponry" (which the author of (1) assumes is bad policy). The author of (2) reports the RAND expert as proposing that "keyboarding" replace "typing" in order to make the activity it denotes more likely to be learned by mid- and high-level managers.

While it doesn't take much for one to make a felicitous metalinguistic proposalunlike other metalinguistic advisories no special authority or social position is required-

\footnotetext{
${ }^{3}$ See Cameron (1995, Ch. 2) for discussion of authority and stylistic rules enforced by editors.

${ }^{4}$ http://en.hebrew-academy.org.il/mission-and-vision/
} 
getting a metalinguistic proposal to have its intended perlocutionary effect is very demanding. It requires getting one's audience to adopt the proposed use. Call a successful metalinguistic proposal one in which the audience does adopt the proposed use; otherwise it is unsuccessful (even if felicitous). ${ }^{5}$ It is unlikely that the RAND expert's proposal to rebrand "typing" as "keyboarding" was successful, for example, given the relative infrequency of "keyboarding" versus "typing" ("typing" occurs 2,136 times in the 2015-2017 portion of the Corpus of Contemporary American English, while "keyboarding" occurs only 7 times). ${ }^{6}$ If one's intended audience is large-all speakers of English, say-then it is extremely unlikely that one's proposal will be successful. ${ }^{7}$ But by restricting one's intended audience, or by restricting the scope of the proposal to a single conversation or topic, one increases the likelihood of making a successful metalinguistic proposal. In the next section, I discuss some experiments that show successful small-scale metalinguistic proposals in action.

\section{Conceptual pacts as successful small-scale metalinguistic proposals}

Metalinguistic proposals play an important role in a common conversational situation: deciding what expression to use to refer to a particular object. Brennan and Clark (1996) conducted experiments on the way interlocutors come to use the same terms to refer to an object over time, a process they call lexical entrainment. They offer evidence in favor of an intentional, dynamic, partner-specific process of lexical entrainment, which they call the formation of a "conceptual pact". Brennan and Clark informally describe the process of forming a conceptual pact as involving a speaker "proposing" a term to refer to an object; the proposal is then either accepted or rejected by the audience (sometimes the audience proposes a different term for the object). The formation of a conceptual pact can be understood as an audience adopting a metalinguistic proposal (in the sense described in the previous section) made by the speaker.

Brennan and Clark examine the formation of conceptual pacts using a series of matching tasks, in which two participants, one "director" and one "matcher", separated by a barrier, were each given a set of cards with pictures of objects on them (dogs, cars, fish, shoes, etc.), and instructed to collaborate to get the matcher's cards to mirror the order of the director's cards. The order of the director's cards was set by an experimenter, and the director and matcher could discuss as much as necessary to reproduce the director's card order. In the following passage, Brennan and Clark illustrate the process of forming a conceptual pact:

When directors first proposed a term like the pennyloafer on those trials, their partners generally accepted the conceptualization it implied with

\footnotetext{
${ }^{5}$ See Bach and Harnish (1979, pp. 55-57) for discussion of different conceptions of felicity conditions and success conditions.

${ }^{6}$ See Davies (2008-).

${ }^{7}$ Compare Cappelen's (2018) arguments that the meaning of expressions in public language is not within any individual's control.
} 
explicit acknowledgements like yeah and okay. If they didn't accept the conceptualization for some reason, the two would work to find terms they could agree on, as here:

Director: a docksider

Matcher: a what?

Director: um

Matcher: is that a kind of dog?

Director: no, it's a kind of um leather shoe, kinda preppy pennyloafer

Matcher: okay, okay, got it

Thereafter, the director referred to this object as the pennyloafer. Sometimes, it was the matcher who proposed the conceptualization they agreed on:

Director: another fish, the most realistic looking one with the pink stripes, green and pink

Matcher: a rainbow trout?

Director: yeah, yeah

From then on, the director referred to the fish as the rainbow trout. As these examples demonstrate, partners collaborated to establish conceptualizations acceptable to both of them. (Brennan and Clark, 1996, p. 1487)

Brennan and Clark find evidence that conceptual pacts are very local: they are formed between particular pairs of speakers and addressees. Depending on the conversational history one has with one's addressee, one will select different lexical items to refer to a particular object. For example, if a pair of director and matcher have referred to a shoe as a "loafer" in a previous experimental interaction, they are more likely to use that term in a new experimental matching task than if one of the participants is replaced with a new participant. And when a conceptual pact is "broken"-when a term that was previously proposed and accepted by a pair of speaker and addressee is replaced by a new term used to refer to the relevant object-addressees are slower to process those referring expressions than when they encounter a new referring expression from a new interlocutor (Metzing and Brennan, 2003).

The formation of a conceptual pact is not automatic, even given extended contactBrennan and Clark cite an example of a pair of experimental participants who persistently refuse to establish a conceptual pact when referring to a picture of a dog-one participant persists in referring to it as a "red dog", the other as a "red lab", even while both are able to successfully identify the referent, neither adopts the other's metalinguistic proposal for how to refer to the dog until the eighth and final round of the conversation (Brennan and Clark, 1996, p. 1493). That exchange offers several examples of metalinguistic proposals that are felicitous in all illocutionary respects, but which are unsuccessful: the intended perlocutionary effect, that the audience adopt the proposed way of referring to the intended referent, is not achieved. 
As a more consequential example of a refusal to enter into a conceptual pact, Brennan and Clark cite the example of a " 1975 trial of a Boston physician who was charged with murder for performing an abortion", in which "the prosecutor referred to the aborted fetus throughout as a baby, whereas the defense lawyer referred to it throughout as a fetus (Danet, 1980)" (Brennan and Clark, 1996, p. 1492). The cooperative norms of normal conversation are radically different in the adversarial context of a murder trial, and such contexts reveal the possibility that metalinguistic proposals can be subject to systematic failure to achieve their intended perlocutionary effects. The next section discusses one philosophically significant category of such systematic failure.

\section{Essentially contested concepts and metalinguistic provocations}

Gallie (1956) introduces the notion of an "essentially contested concept", in which "the proper use of" particular expressions (Gallie focuses on "art", "democracy", and "Christian tradition") "inevitably involves endless disputes about their proper uses on the part of their users" (Gallie, 1956, pp. 169). Gallie offers seven criteria that are meant to characterize essentially contested concepts (Collier et al., 2006, p. 212): (I) appraisive character, (II) internal complexity, (III) diverse describability, (IV) openness, (V) adversarial use, (VI) the term's meaning is anchored to an original exemplar, and (VII) "continuous competition for acknowledgement as between the contestant users of the concept, enables the original exemplar's achievement to be sustained and/or developed in optimum fashion" (Gallie, 1956, p. 180)

The meaning and significance of each of these criteria has been disputed (see Collier et al. 2006 for an overview). For example, Väyrynen (2014) argues persuasively that what makes a concept essentially contestable is independent of criterion (I), its "appraisive" or evaluative character, contrary to standard accounts that claim essential contestability helps illuminate what it is to be an evaluative concept. In this section, I will focus on criterion $(\mathrm{V})$, adversarial use, because it raises an interesting question for how the felicity conditions of metalinguistic proposals should be understood.

According to Gallie's criterion (V), for a concept to be essentially contested, rather than just contestable, it has to be the case that:

[E]ach party recognizes the fact that its own use of it is contested by those of other parties, and that each party must have at least some appreciation of the different criteria in the light of which the other parties claim to be applying the concept in question. More simply, to use an essentially contested concept means to use it against other uses and to recognize that one's own use of it has to be maintained against these other uses. Still more simply, to use an essentially contested concept means to use it both aggressively and defensively. (Gallie, 1956, p. 172)

Criterion (V), adversarial use, can be cast in terms of competing metalinguistic proposals: The use of an expression is adversarial in Gallie's sense just in case: 
1. A speaker $\mathrm{S}$ makes a metalinguistic proposal for an expression,

2. knowing that a competing and incompatible metalinguistic proposal for the same expression has been or will be made,

3. and that the speaker making the competing metalinguistic proposal would not accept speaker S's proposal.

One contemporary example that meets the conditions for an adversarial use of an expression is "assault weapon" or "assault rifle", introduced in $\S 1$, above. The National Shooting Sports Foundation (NSSF), the firearm industry's trade association, proposes that "assault rifle" should be understood as follows: "An assault rifle is fully automatic - a machine gun. Automatic firearms have been severely restricted from civilian ownership since 1934". That is, the military-style semi-automatic rifles that are often used in mass shootings of civilians in the U.S. do not count as assault rifles according to this proposal. And those responsible for this proposal are aware that there is a competing ("Californian") metalinguistic proposal for how to understand "assault weapon":

If someone calls an AR-15-style rifle an 'assault weapon,' he or she either supports banning these firearms or does not understand their function and sporting use, or both. Please correct them. 'Assault weapon' is a political term created by California anti-gun legislators to ban some semi-automatic rifles there in the 1980s. ${ }^{8}$

In contrast, the "Californian" legal understanding of "assault rifle" is much more inclusive: any semiautomatic rifle with a detachable magazine and a pistol grip counts as an assault rifle. ${ }^{9}$ The California definition captures what advocates of banning "assault rifles" tend to have in mind by the expression, namely a particular military-style look of rifle (so-called "AR" or "AK"-style weapons, which have detachable magazines and pistol grips).

The NSSF's proposal for the meaning of "assault rifle" meets the conditions for an adversarial use of the expression: the NSSF is aware that there is a competing and incompatible ("Californian") metalinguistic proposal for how "assault rifle" should be used, and that those responsible for the competing proposal would reject the NSSF's proposed use. And yet the NSSF persists in making its proposal. Given that a felicitous metalinguistic proposal requires the speaker to intend that her audience come to adopt the proposed use, what happens in the case of adversarial use, where the speaker knows that at least part of the audience would not accept the proposed use? If it's the case, as held by Davidson (1980), that one can't intend to do something if one believes that

\footnotetext{
${ }^{8}$ https://www.nssf.org/msr/

${ }^{9}$ https://oag.ca.gov/firearms/bullet-button-assault-weapon. The California legal definition of "assault rifle" also includes the requirement that it be a centerfire rifle, which refers to the type of ammunition used, in which the primer (the propellant for the bullet) is located in the center of the cartridge case, rather than being located at the rim of the cartridge, as in rimfire cartridges. Modern firearms tend to use centerfire ammunition.
} 
it is impossible, then knowing that the audience won't adopt the proposed use means that the perlocutionary intention required for a felicitous metalinguistic proposal will be missing when one makes an adversarial metalinguistic proposal for an expression.

One might try to avoid infelicity in the case of adversarial uses of metalinguistic proposals by holding that someone who is proposing the competing "Californian" meaning for "assault rifle" is not part of the intended audience for the NSSF proposal, so the speaker is not intending someone to adopt a use that one knows will be rejected. But the NSSF passage explicitly instructs its audience to "correct" anyone using "assault rifle" in the competing way, which would require addressing them with a metalinguistic proposal. Rather than trying to find a way for adversarial uses of metalinguistic proposals to come out felicitous, however, recognizing that they are "unhappy" in one particular way should be seen as a positive aspect of this account of metalinguistic proposals, not a problem. The account captures the way adversarial metalinguistic proposals will, in a certain respect, fail. But with essentially contested expressions like "assault rifle", the speaker can also target the subset of the audience whose minds are not made up about how to use the contested expression; in that respect, the speaker is performing multiple speech acts: an infelicitous proposal (directed at those who the speaker knows will reject the proposed use), and a felicitous proposal, directed at those who the speaker thinks are open minded or in agreement with the proposed use. ${ }^{10}$

Related to adversarial uses of metalinguistic proposals, in which the speaker knows that the audience will reject the proposed use, but makes the proposal anyway, are metalinguistic provocations. If the speaker's perlocutionary intention is not for the audience to adopt the use that the speaker believes is a good idea, but to get the audience to overtly disagree with the speaker's belief that a particular use is a good idea, then she has performed a metalinguistic provocation. ${ }^{11}$ A speaker might want to perform a metalinguistic provocation for good reasons (stimulating vigorous debate in a classroom or the Agora), or for bad reasons (derailing conversation by trolling one's political opponents). Here is a candidate metalinguistic provocation:

(3) Katz and Stich (in this volume) think that the data base for linguistics consists in the intuitions we have about grammaticality, ambiguity, etc. I need a name for this view. I shall call it the Wrong View. (Fodor, 1981, p. 198)

Fodor can't plausibly intend Katz and Stich and those who agree with them to adopt "the Wrong View" as the name for their view. For that audience, (3) might be intended as a metalinguistic provocation, not a proposal. Or it might be another type of speech act altogether-namely, a joke. Or Fodor might be deliberately making an utterance

\footnotetext{
${ }^{10}$ The existence of different communicative intentions being directed at different audiences with a single utterance is discussed in the literature on political "code words" (Khoo, 2017) and "dogwhistles" (Saul, 2018).

${ }^{11}$ Thanks to an anonymous referee for asking for discussion of this possibility: "it is worth getting clear on how one knows whether something is just a metalinguistic proposal versus an invitation to fight about meaning".
} 
that is ambiguous between two or more of these speech acts (see Weiser 1974 and Bach and Harnish 1979, pp. 101-102 for discussion of deliberately ambiguous speech acts). ${ }^{12}$

\section{Ordinary language philosophy and metalinguistic proposals}

Metalinguistic proposals can also illuminate an ongoing debate about the methods of ordinary language philosophy. Practitioners of mid-century "ordinary language philosophy" notoriously made claims about how "we" use English expressions, without conducting large-scale experimental or corpus-based surveys of how English speakers do in fact use the relevant expressions (Mates, 1958; New, 1966). Some of those observations about how "we" use an expression conflicted with each other, and sometimes times their descriptions of how "we" use the expressions in question does not accord with evidence from experimental investigations of how speakers in fact use those expressions (Hansen, 2014; Hansen and Chemla, 2015; Hansen, 2017). For example, J.L. Austin tells a story about running over a child's go-cart in order to motivate a distinction between the meaning of doing something "intentionally" and doing something "deliberately", and he proposes we should describe the action of running over the go-cart in the following way:

However 'odd' is may sound, I feel little doubt that we should say here that we did run over the go-cart deliberately and that we should not care to say we ran over it intentionally. We never intended to run over it. (Austin, 1966, p. 432)

Hansen and Chemla (2015) investigated whether ordinary speakers agreed with Austin's assessment of "what we should say" about this case, and found that experimental participants could easily be swayed between saying that the go-cart was run over "deliberately" or "intentionally", depending on how the case was "glossed" (Austin glosses it as being not intentional because it was not intended); and when the case is presented without any gloss, participants appeared indifferent between the two descriptionsthere was not a significant difference between the rates of "intentionally"-responses and "deliberately"-responses. That pattern of responses indicates that Austin is shaping how we describe this case, rather than correctly describing how we do, or would, describe it.

Some defenders of ordinary language philosophy have embraced the idea that ordinary language philosophers were not aiming to accurately represent the way people do in fact use language. Instead, it has been argued that claims about how "we" use an expression are not descriptive claims about frequency of use. Instead, such claims should

\footnotetext{
${ }^{12}$ Deliberately leaving it open whether one is performing a metalinguistic proposal or a provocation would be a way, as an anonymous referee puts it, of "trial-ballooning a metalinguistic proposal to see if one can get away with it". If the audience rejects the use that is being "trial-ballooned", the speaker can insist that it was intended as a provocation, or a joke.
} 
be understood as either (a) descriptions of "objective facts about linguistic norms""legitimate use" (Sandis, 2010), or (b) as speech acts possessing some form of prescriptive force (see Mates's 1958 comments on Ryle's distinction between normative "use" and merely descriptive "usage", and Cavell 1958).

An important and unanswered worry about the first way of spelling out the normativity of the claims of ordinary language philosophers, (a), is that there is pervasive variation between and within speakers in how they use expressions, and there is no convincing account of how to determine what the "objective facts" about the "legitimate" and "illegitimate" uses of an expression are (Jackman, 2001; Lassiter, 2008). Speakers often have strong beliefs about what the "legitimate" and "illegitimate" uses of expressions are, and can institute lexical norms by criticizing and correcting perceived "misuses" of certain expressions (Niedzielski and Preston, 2000). But there is also variation among the norms that speakers institute-even pronouncements about proper use coming from official bodies like the L'Académie française or the Accademia dela Tosca don't automatically exclude or override competing norms of use (Jackman, 2001, p. 321). What norms concerning the "legitimate" use of lexical items one endorses is a "forensic" (ethical, political, legal) issue, rather than a purely linguistic one. ${ }^{13}$

Regarding the second way of trying to capture the normative character of ordinary language philosophy, (b) namely that claims about what "we say" possess some form of prescriptive force, critics have dismissed the idea that ordinary language philosophers possessed a form of authority that could give statements about what "we say" the status of authoritative metalinguistic directives. For example, Jackman (2001) writes that: "[I]f if Oxford usage were authoritative for English speakers in general, then they could claim that knowing how words were used in their group was enough to know how 'we' used such words" (Jackman, 2001, pp. 320-321). But Oxford professors of philosophy don't have the right kind of authority to issue authoritative metalinguistic directives requiring, forbidding, or allowing speakers of English to use an expression in some particular way.

As an alternative to the implausible idea that ordinary language philosophers are making authoritative metalinguistic directives, Jackman (2001) discusses an account of the distinctive character of the claims made by ordinary language philosophers that invokes the "dialectical abilities" of the speaker:

Some speakers may (through their ability to produce distinctions, precisifications, counterexamples and equivalencies) be able to persuade other speakers about how various terms in their language should be used. Such speakers could, like officially recognized authorities, make categorical declaratives that hold good for the entire community. If others were not initially inclined to share their characterizations, they could be persuaded that they were mistaken in doing so. (Jackman, 2001, p. 322) $)^{14}$

\footnotetext{
${ }^{13}$ See Stainton (2016) for this use of "forensic" in relation to the content of what is stated.

${ }^{14} \mathrm{~A}$ "[categorial] declarative" is a kind of metalinguistic directive speech act discussed by Cavell (1958), which I will examine below.
} 
Jackman's "dialectical" proposal for how to understand the claims about "what we say" made by ordinary language philosophers fits nicely with Cavell's (1958) defense of the methods of ordinary language philosophy, which V.C. Chappell (1964) described as "the most detailed explanation and defense of the procedures of ordinary language philosophers that has yet appeared"- - a description which remains true over 50 years later. Cavell's notion of a "categorial declarative", which is his account of what kind of speech act is being performed when an ordinary language philosopher makes a claim about "what we say" when we use a particular expression, is a "rule-description", playing a prescriptive role akin to the role played by an utterance of "We keep our promises (that is the sort of thing a promise is)" (Cavell 1958, p. 195). Hansen (2017) argues that for Cavell, categorial declaratives are not empirical descriptions of use, but should be understood as metalinguistic proposals for how an expression should be used, just as an utterance of "We keep our promises" need not be a description of what we in fact do-it can be a proposal for how we should act.

When the statements of the ordinary language philosophers concerning "what we say" are understood as metalinguistic proposals, that provides a response to Mates's (1958) challenge to explain how ordinary language philosophers are entitled to make claims about "what we say" without engaging in experimental or corpus-based surveys of how people do in fact use language. The entitlement to make such claims comes not from having collected a representative sample of actual use; instead, every speaker of the language is entitled to make metalinguistic proposals for how expressions should be used. What speakers are not entitled to is that their audience will accept their proposal. ${ }^{15}$

While Jackman's "dialectical" conception of authority fits nicely with Cavell's defense of the methods of ordinary language philosophy, Jackman argues that it cannot be the case that ordinary language philosophers are making proposals for how expressions should be used, because it would

allow the philosopher to make extremely [revisionary] claims about how our ordinary terms should be used, and this seems to be precisely the sort of procedure that the ordinary language philosophers saw themselves as opposing. (Jackman, 2001, p. 322)

Jackman is assuming a standard reading of the methodology of ordinary language philosophy, according to which it criticizes "philosophical" uses of expressions for diverging from ordinary use. There are undoubtedly examples of ordinary language philosophers arguing this way. A clear example is Malcolm (1951), who argues that the "philosopher's" use of the sentence "I am here", as an example of an "unshakeable

\footnotetext{
${ }^{15}$ Cavell, in a later essay (1976), analogizes claims about "what we say" to the judgment of an art critic, which cannot be confirmed or disconfirmed in the way an empirical descriptive claim can be. According to Cavell, the judgments of an art critic are vindicated only insofar as they bring about the right kind of sympathetic response in the audience (Cavell, 1976, p. 87) For further discussion of Cavell's analogy between the statements of ordinary language philosophers and the judgments of an art critic, see Hansen $(2017, \S 4.3)$.
} 
truth", is actually "nonsense" because it diverges from the "natural usage" of "I am here", which is to "inform someone of our whereabouts". But the arguments in Austin $(1957,1958,1966)$ regarding the expressions "accident" and "mistake", "pretending to drive a racing-car" and "pretending to be driving a racing-car", and "deliberately" and "intentionally", respectively, do not simply involve appeals to the "ordinary" meaning of those expressions. Instead, Austin makes proposals for distinguishing the meaning of each pair of expressions, and makes the case that his distinctions are the "correct" ones, even when they conflict with the use of ordinary speakers (such as the "learned judge" in the case of Regina v. Finney, whose judgment is full of "faults" about the use of various terms of excuse) (Austin, 1957, p. 23).

In Austin's most explicit discussion of his methods, he explicitly rejects treating ordinary language as "the last word" - that is, as a definitive method of limning reality: "Certainly, then, ordinary language is not the last word: in principle it can everywhere be supplemented and improved upon and superseded" (Austin, 1957, p. 11). His notion that ordinary language is "the first word" should be understood as the claim that paying attention to distinctions encoded in ordinary language offers a fruitful discovery procedure for distinctions that might have otherwise been overlooked in armchair philosophical theorizing. Austin's investigation of excuses is driven by the idea that examining the nuances of ordinary language in this area can turn up important distinctions in the phenomena themselves, because excuses are a "matter both contentious and practically important for everybody, so that ordinary language is on its toes" (p. 11). Even given that there is reason to think that ordinary language should reflect real distinctions concerning excuses, Austin goes on to say that the examination of ordinary language needs to be supplemented with a study of excuses in the law, because

a constant stream of actual cases, more novel and more tortuous than the mere imagination could contrive, are brought up for decision - that is, formulae for docketing them must somehow be found. Hence it is necessary first to be careful with, but also to be brutal with, to torture, to fake and to override, ordinary language...

And even more striking given the standard characterization of the methods of ordinary language philosophy, Austin says that the resources provided by ordinary language and the law for the study of excuses should be supplemented with the "source-book" of psychology, which he says includes "anthropology and animal behaviour" (p. 14). Psychology is important, Austin says, because, like the law it "produces novel cases, but it also produces new methods for bringing phenomena under observation and study: moreover, unlike the law, it has an unbiased interest in the totality of them and is unpressed for decision" (p. 12). Only by triangulating on the underlying phenomena using all of these resources does Austin think he can approach "the Last Word" on the phenomenon of excuses. While Jackman's worry about the "charismatic" conception of authority used in ordinary language philosophy may apply to Malcolm's (1951) crude argument from ordinary language, it does not correctly characterize what Austin says about his own investigation of excuses, namely that he is open to the "constant need 
to supplement, to revise and to supersede the classifications of both ordinary life and the law". It is this more sophisticated version of the methodology of ordinary language philosophy that Cavell (1958) defends, and for which metalinguistic proposals play a central role.

\section{Metalinguistic Proposals and Related Concepts}

How do metalinguistic proposals and authoritative metalinguistic directives relate to the rich variety of neighboring theoretical concepts, such as "conceptual engineering" (Cappelen, 2018), "conceptual ethics" (Burgess and Plunkett, 2013), "lexical warfare" (Ludlow, 2014), "metalinguistic negotiation" (Plunkett and Sundell, 2013), "linguistic interventions" (Sterken, 2019), and "ameliorative projects" (Haslanger, 2012)?

Metalinguistic proposals concern how we should use particular linguistic expressions. They therefore do not necessarily concern concepts, unlike Haslanger's "ameliorative projects", which involve "developing concepts" that help us achieve certain legitimate purposes (Haslanger, 2012, p. 366), and they do not necessarily concern linguistic meaning, content, or any other semantic notions either. Embracing metalinguistic proposals therefore does not require any particular view about what concepts or word meanings are, or even whether they exist. That distinguishes my account of metalinguistic directives from Ludlow's (2014) conception of "lexical warfare", which involves conflicts over what (temporary) meaning some particular word should have in a conversational micro-language, and from Sterken's (2019) account of "linguistic interventions", which are "communicative activities on the part of a speaker that (intentionally and strategically) attempt to change the word-meaning pairs in circulation".

To demonstrate the classificatory utility of the category of metalinguistic proposals, consider again the examples of "assault rifle", "battle rifle" (1) and "keyboarding" (2) that opened this paper. These are clearly metalinguistic proposals: they are expressions of the belief that using or not using expressions in certain ways is a good idea, and they express the perlocutionary intention that the audience adopt the proposed use. But how would they be classified using neighboring theoretical categories? They are not moves in a metalinguistic negotiation, because they are explicit (they could be moves in what Plunkett and Sundell call a "canonical dispute"; see Plunkett and Sundell 2013, 2019 for discussion of the implicitness of metalinguistic negotiation); though these proposals are in the spirit of Haslanger's ameliorative projects, (1) and (2) are not developing new concepts to attach to the pronouns they are concerned with-they are arguing just that we should act in a certain way: namely, to use or not use particular expressions to talk about certain objects or activities. And while these proposals might sound like acts of "lexical warfare", it's not the case that the speakers who utter (1) and (2) intend to change the meaning of their target expressions. The structure of what is going on in (1) and (2) is best described as the making of metalinguistic proposals.

The category of metalinguistic proposals is also helpful for characterizing certain types of linguistic engineering projects that have a deeper philosophical significance as well. Consider the following two claims, from Dembroff and Wodak (2018, p. 372): 
Moderate Claim We have a duty not to use binary gender-specific pronouns (he or she) to refer to genderqueer individuals like Angel Haze.

Radical Claim We have a duty not to use gender-specific pronouns to refer to anyone, regardless of their gender identity.

How should we understand Dembroff and Wodak's two claims? They aren't cases of metalinguistic negotiation, because they aren't implicit; they aren't part of an ameliorative project because they don't concern the concepts associated with gender-specific pronouns; and they aren't examples of "lexical warfare" because they aren't aiming to change the meaning associated with those pronouns. ${ }^{16}$ And Dembroff and Wodak's claims don't fit easily within any of the three categories of things that Cappelen (2018, p. 137) considers conceptual engineering could be about: Dembroff and Wodak's claims are not about concepts; their claims do not aim to change the meaning of gender-specific pronouns; and their claims are not trying to change the world in Cappelen's sense of "changing what gender, freedom, salad, marriage, etc. [the things target expressions refer to] are". Instead, Dembroff and Wodak's claims are best described as metalinguistic proposals, which aim to change the way we act-more specifically, they aim to change the way we use certain linguistic expressions. ${ }^{17}$

\section{Conclusion}

In this paper, I have described the felicity and success conditions for metalinguistic proposals, a type of directive speech act, described experimental conditions in which successful metalinguistic proposals are performed, examined situations in which there are systematic failures of those success conditions, distinguished metalinguistic proposals from metalinguistic provocations, and argued that metalinguistic proposals play an important but overlooked role in the methodology of ordinary language philosophy. Acknowledging the existence and success conditions of metalinguistic proposals does not require embracing any particular theories of the nature of concepts or linguistic meaning as some neighboring theories of "lexical warfare" or "ameliorative projects" do, and metalinguistic proposals, unlike "metalinguistic negotiation", do not need to be implicit (though they can be individual moves in a "canonical dispute"). For those reasons, metalinguistic proposals are a valuable addition to our theoretical toolkit for

\footnotetext{
${ }^{16}$ Dembroff and Wodak's claims can plausibly be characterized in terms of Sterken's (2019) notion of a "linguistic intervention", since they propose to change the word-meaning pairs in circulation.

${ }^{17}$ They themselves refer to what they are doing as making a proposal: "Finally, we are decidedly not declaring that using they or ze for everyone would be a panacea. The oppression, discrimination, and persecution faced by transgender persons and other gender minorities is alarming and multifaceted. So is the essentialist misogyny to which gender oppression is often tethered. It would be foolhardy to think there is a silver bullet to defeat these threats, let alone one as simple as a change in pronouns. But that is no reason to ignore our proposal that we should stop using gender-specific pronouns" (Dembroff and Wodak, 2018, p. 375).
} 
thinking about aspects of language that we may want to rearrange to better serve our purposes.

\section{References}

Austin, J.L. (1956-1957). "A Plea for Excuses". Proceedings of the Aristotelian Society $57,1-30$.

Austin, J.L. (1958). "Pretending”. Proceedings of the Aristotelian Society 32, 261-294.

Austin, J.L. (1966). “Three Ways of Spilling Ink". The Philosophical Review 75(4), 427-440.

Austin, J.L. (1975). How to Do Things With Words (2nd ed.). Oxford: Oxford University Press.

Bach, Kent and R. M. Harnish (1979). Linguistic Communication and Speech Acts. Cambridge, Massachusetts: MIT Press.

Barker, Chris (2002). "The Dynamics of Vagueness”. Linguistics and Philosophy 25(1), $1-36$.

Brennan, Susan E. and H. H. Clark (1996). "Conceptual Pacts and Lexical Choice in Conversation". Journal of Experimental Psychology: Learning, Memory, and Cognition 22(6), 1482-1493.

Burgess, Alexis and D. Plunkett (2013). "Conceptual Ethics I". Philosophy Compass 8(12), 1091-1101.

Cameron, Deborah (1995). Verbal Hygiene: The Politics of Language. London: Routledge.

Cappelen, Herman (2018). Fixing Language: An Essay on Conceptual Engineering. Oxford: Oxford University Press.

Cavell, Stanley (1958). "Must We Mean What We Say?”. Inquiry 1, 172-212.

Cavell, Stanley (1976). "Aesthetic Problems of Modern Philosophy". In Must We Mean What We Say?, pp. 73-96. Cambridge: Cambridge University Press.

Chappell, V.C. (Ed.) (1964). Ordinary Language. Englewood Cliffs, New Jersey: Prentice-Hall.

Collier, David, F. Daniel, and A. O. Maciuceanu (2006). "Essentially Contested Concepts: Debates and Applications". Journal of Political Ideologies 11(3), 211-246.

Danet, Brenda (1980). “'Baby' or 'Fetus'?: Language and the Construction of Reality in a Manslaughter Trial”. Semiotica 32(3-4), 187-219. 
Davidson, Donald (1980). “Intending”. In Essays on Actions and Events, pp. 83-102. Oxford: Oxford University Press.

Davies, Mark (2008-). The Corpus of Contemporary American English (COCA): 520 Million Words, 1990-present. http://corpus.byu.edu/coca/.

Dembroff, Robin and D. Wodak (2018). "He/She/They/Ze". Ergo: An Open Access Journal of Philosophy 5, 1-36.

Fodor, Jerry A. (1981). "Introduction: Some Notes on What Linguistics Is About". In N. Block (Ed.), Readings in the Philosophy of Psychology, Volume 2, pp. 197-207. Cambridge, Massachusetts: Harvard University Press.

Gallie, W.B. (1955-1956). "Essentially Contested Concepts". Proceedings of the Aristotelian Society 56, 167-198.

Hagège, Claude (2005). "On the Part Played by Human Conscious Choice in Language Structure and Language Evolution". In Z. Frajzyngier, A. Hodges, and D. S. Rood (Eds.), Linguistic Diversity and Language Theories, Studies in Language Comparison, pp. 105-117. Amsterdam: John Benjamins.

Hansen, Nat (2014). "Contemporary Ordinary Language Philosophy". Philosophy Compass 9(8), 556-569.

Hansen, Nat (2017). “Must We Measure What We Mean?”. Inquiry 60(8), 785-815.

Hansen, Nat and E. Chemla (2015). "Linguistic Experiments and Ordinary Language Philosophy”. Ratio 28(4), 422-445.

Haslanger, Sally (2012). Resisting Reality: Social Construction and Social Critique. Oxford: Oxford University Press.

Jackman, Henry (2001). "Ordinary Language, Conventionalism and a priori Knowledge". dialectica 55(4), 315-325.

Khoo, Justin (2017). "Code Words in Political Discourse". Philosophical Topics 45(2), $33-64$.

Langton, Rae (1993). "Speech Acts and Unspeakable Acts". Philosophy \& Public Affairs 22(4), 293-330.

Lassiter, Daniel (2008). "Semantic Externalism, Language Variation, and Sociolinguistic Accommodation". Mind \& Language 23(5), 607-633.

Ludlow, Peter (2014). Living Words: Meaning Underdetermination and the Dynamic Lexicon. Oxford: Oxford University Press. 
Malcolm, Norman (1951). "Philosophy for Philosophers". The Philosophical Review 60(3), 329-340.

Mates, Benson (1958). "On the Verification of Statements about Ordinary Language". Inquiry 1(1), 161-171.

Metzing, Charles and S. E. Brennan (2003). "When Conceptual Pacts are Broken: Partner-Specific Effects on the Comprehension of Referring Expressions". Journal of Memory and Language 49, 201-213.

New, C.G. (1966). “A Plea for Linguistics”. Mind 75(299), 368-384.

Niedzielski, Nancy A. and D. R. Preston (2000). Folk Linguistics. The Hague: Mouton de Gruyter.

Plunkett, David and T. Sundell (2013). "Disagreement and the Semantics of Normative and Evaluative Terms". Philosophers' Imprint 13(23), 1-37.

Plunkett, David and T. Sundell (2019). "Metalinguistic Negotiation and Speaker Error". Forthcoming in Inquiry.

Sandis, Constantine (2010). "The Experimental Turn and Ordinary Language". Essays in Philosophy 11(2), 181-196.

Saul, Jennifer (2018). "Dogwhistles, Political Manipulation, and Philosophy of Language". In D. Fogal, D. W. Harris, and M. Moss (Eds.), New Work on Speech Acts, pp. 360-383. Oxford: Oxford University Press.

Stainton, Robert J. (2016). "Full-on Stating”. Mind \& Language 31(4), 395-413.

Sterken, Rachel Katharine (2019). "Linguistic Intervention and Transformative Communicative Disruptions". In H. Cappelen and D. Plunkett (Eds.), Conceptual Engineering and Conceptual Ethics, pp. 1-22. Oxford: Oxford University Press.

Väyrynen, Pekka (2014). "Essential Contestability and Evaluation". Australasian Journal of Philosophy 92(3), 471-488.

Weiser, Ann (1974). "Deliberate Ambiguity". In Chicago Linguistic Society, Volume 10, Chicago, pp. 721-730. 